\section{IgG4-related Disease Manifesting as Pachymeningitis and Aortitis}

\section{To the Editor:}

A 57-year-old Iraqi woman presented with a 3-year history of right temporal headache, weight loss, and fatigue. She denied fevers, chills, night sweats, visual changes, jaw claudication, joint pain, or focal neurologic symptoms. Her medications included aspirin and captopril. She had received 1 month of oral prednisone (dose unclear) 4 months prior to presentation. Her vital signs were unremarkable, including symmetric blood pressures in all 4 limbs. She had scalp tenderness without temporal artery nodularity and had bruits of the right carotid, right brachial, and bilateral femoral arteries. The examination was otherwise unremarkable.

She was anemic (hematocrit $27.2 \%$ ) with erythrocyte sedimentation rate (ESR) $115 \mathrm{~mm} / \mathrm{h}$ and C-reactive protein (CRP) $3.3 \mathrm{mg} / \mathrm{dl}$ Cerebrospinal fluid (CSF) was clear and colorless and showed a lymphocytic pleiocytosis (24 white blood cells with $93 \%$ lymphocytes) with mildly elevated protein $(71 \mathrm{mg} / \mathrm{dl})$ and normal glucose $(51 \mathrm{mg} / \mathrm{dl})$. Negative infectious studies of CSF included bacterial, fungal, and mycobacterial cultures, as well as venereal disease research laboratory test, PCR for herpes simplex virus, and cryptococcal antigen. Magnetic resonance imaging of the brain showed diffuse pachymeningeal thickening and enhancement (Figure 1A) without venous sinus thrombosis by computed tomography (CT) venogram. CT of the chest, abdomen, and pelvis revealed thoracic aortitis (Figure 1B).

Rheumatoid factor was $21 \mathrm{IU} / \mathrm{ml}$. Serum antinuclear antibody, antineutrophil cytoplasmic antibody, interferon gamma release assay, rapid plasma reagent, and fluorescent treponemal antibody-absorbed tests were negative, and immunoglobulin G4 (IgG4) level was normal $(54 \mathrm{mg} / \mathrm{dl})$. The differential diagnosis included vasculitis (giant cell vs Takayasu arteritis) and IgG4-related disease (IgG4-RD), with sarcoidosis, malignancy, and infection considered less likely. A $20 \times 2.5 \mathrm{~mm}$ biopsy of the right temporal artery showed no evidence of giant cell arteritis.

Dural biopsy demonstrated dural thickening with a dense lymphoplasmacytic infiltrate, lymphoid aggregates, focal storiform fibrosis, and focal phlebitis (Figure 2A-2C). There were rare eosinophils, abundant interspersed CD68-positive macrophages, and occasional giant cells, but no granulomas. Immunostaining for $\operatorname{IgG} 4$ and $\mathrm{IgG}$ revealed an elevated number of IgG4-positive plasma cells [average of 26 per high-power field (HPF); Figure 2D] and an $\operatorname{IgG} 4 / \operatorname{IgG}$ ratio $>50 \%$. Bacterial, fungal, and mycobacterial stains and cultures were negative and viral cytopathic changes absent. Immunohistochemistry supported an inflammatory process rather than lymphoma.

IgG4-RD manifesting as pachymeningitis and aortitis was diagnosed. Prednisone was initiated at $0.6 \mathrm{mg} / \mathrm{kg} / \mathrm{day}$. Given concomitant severe osteoporosis, steroid-sparing agents in the form of weekly methotrexate and intravenous rituximab (1000 mg twice, 2 weeks apart) were administered 3 and 6 months from the time of diagnosis, respectively. Repeat CT imaging 6 months after initiation of prednisone showed complete resolution of the dural enhancement and marked improvement of the aortitis. Nine months from diagnosis, headaches had resolved and ESR (34 $\mathrm{mm} / \mathrm{h})$ and CRP $(1.0 \mathrm{mg} / \mathrm{dl})$ were markedly improved while she was taking prednisone $8 \mathrm{mg} /$ day and weekly oral methotrexate. Repeat IgG4 level was $18 \mathrm{mg} / \mathrm{dl}$

IgG4-RD is a recently recognized fibroinflammatory entity characterized by tissue infiltration by IgG4-positive plasma cells ${ }^{1}$. It was first described in patients with autoimmune pancreatitis, in whom the presence of identical histological findings in other organs suggested a systemic process. It has since been described in myriad organs, with unifying histopathologic features ${ }^{2}$.

Pathogenesis of IgG4-RD remains unclear. Serum $\mathrm{IgG} 4$ level is elevated in $44 \%-100 \%$ of patients in published series ${ }^{1,3}$. A prozone effect caused by antigen excess may account for a subset of cases with reportedly normal IgG4 level, and may be overcome with serial sample dilutions ${ }^{3}$ (unfortunately not available in our patient). Histologically, a dense lymphoplasmacytic infiltrate in a storiform pattern is characteristic, yet not entirely specific. The abundant macrophages seen in this case are unusual for IgG4-RD in many tissues, but have been reported in meningeal disease $^{4}$. For diagnosis, immunostaining must demonstrate an elevated absolute number of IgG4-positive plasma cells per HPF, and an elevated ratio of IgG4 to IgG-positive plasma cells may aid in confirmation. Mimics, particularly lymphomas, must be excluded ${ }^{1}$.

IgG4-RD has been found to cause a significant proportion of cases of noninfectious aortitis ${ }^{5}$. In contrast, IgG4-RD of the central nervous system is rare, with a few cases of pituitary and meningeal involvement described $^{6}$. Recently, cases of both intracranial and spinal pachymeningitis due to IgG4-RD have been reported; these would previously have been classified as idiopathic hypertrophic pachymeningitis ${ }^{4,6,7}$. Consensus criteria for meningeal IgG4-RD would classify this case as "probable histological features of IgG4-RD" based on histological features and $>10$ IgG4-positive cells per $\mathrm{HPF}^{8}$.

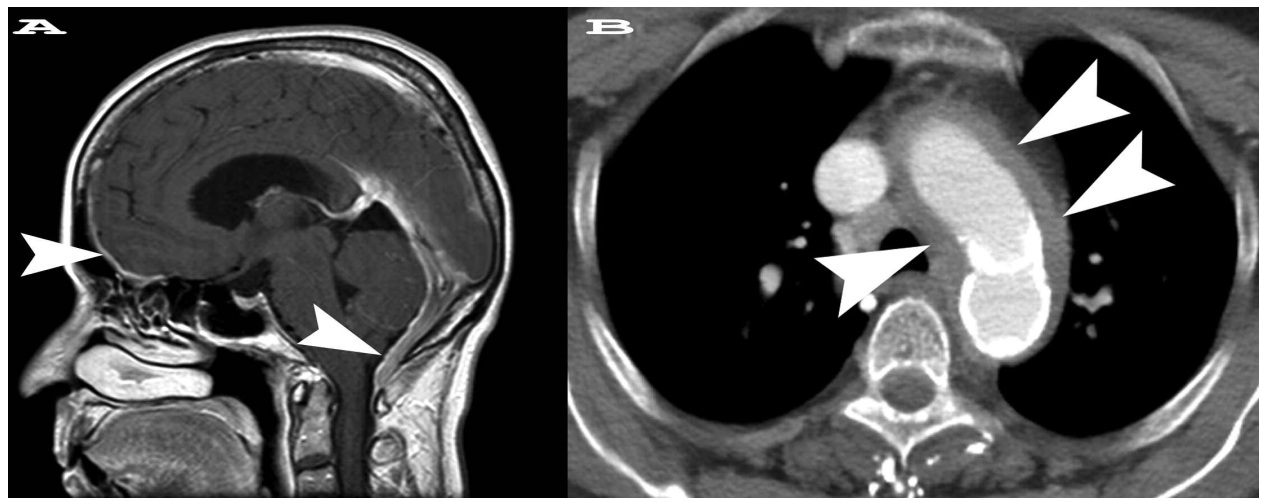

Figure 1. A. Sagittal postcontrast T1-weighted magnetic resonance scan shows diffuse pachymeningeal thickening and enhancement best seen in the anterior and posterior cranial fossa (arrowheads). The anterior cranial fossa arrowhead shows the future site of dural biopsy. The dural thickening had completely resolved on followup imaging 6 months after therapy was initiated. B. Axial postcontrast computed tomography image from the chest shows circumferential wall thickening surrounding the aortic arch and proximal great vessels (arrowheads) consistent with aortitis. There is a small amount of hyperattenuation in the aortic wall because of calcification. On followup imaging, the soft-tissue thickening was almost completely resolved. 

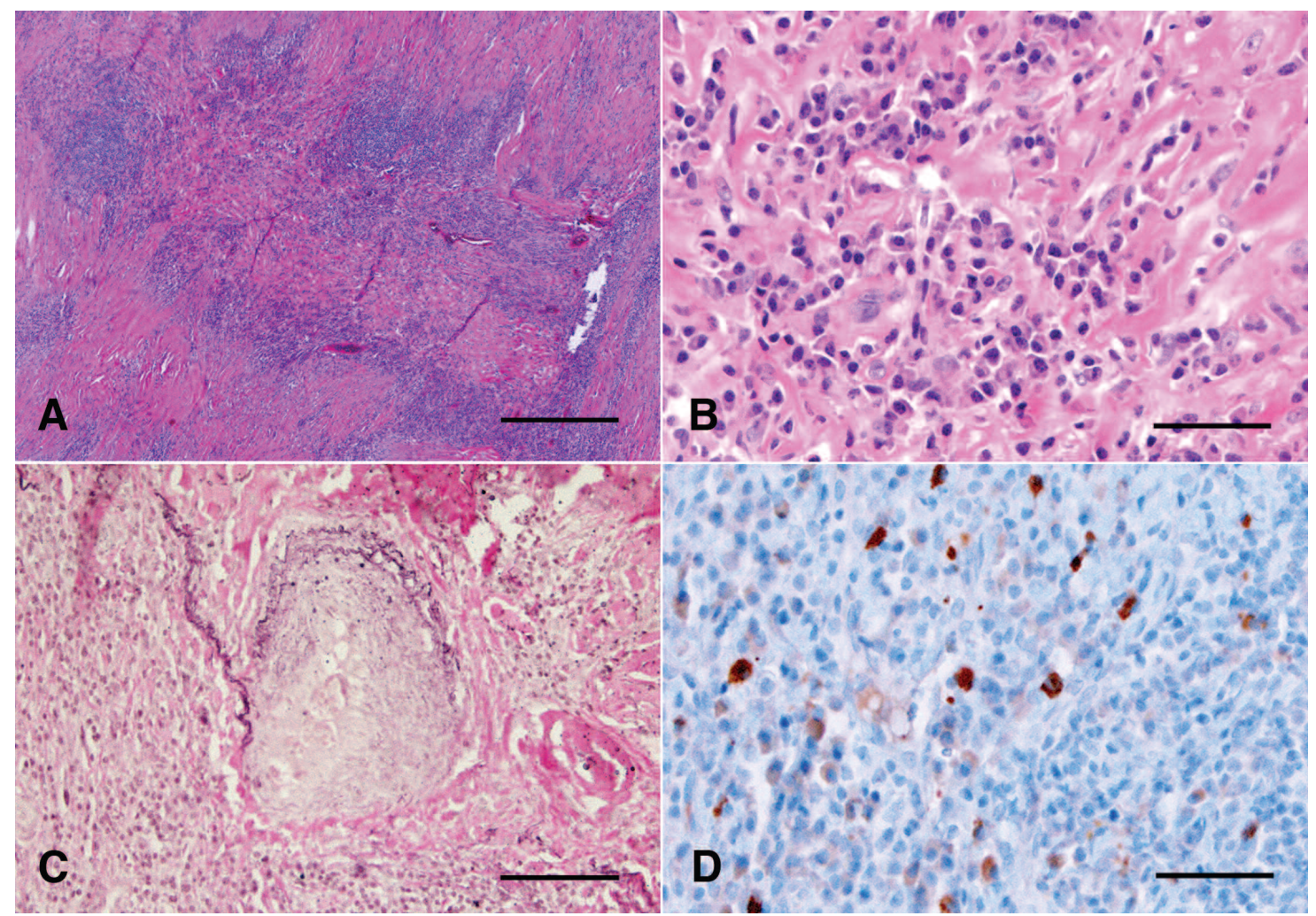

Figure 2. A. Low-power H\&E stained section showing dense inflammatory infiltrate with lymphoid nodules. Bar $=500 \mu \mathrm{m}$. B. High-power H\&E stained section showing plasma cell infiltrate and fibrosis. Bar $=50 \mu \mathrm{m}$. C. Elastin stain showing obliterative phlebitis. Bar $=100 \mu \mathrm{m}$. D. IgG4 immunostain highlights increased IgG4-positive plasma cells (in brown) within and adjacent to a lymphoid nodule. Bar $=50 \mu \mathrm{m}$.

We are aware of 1 other case in the literature of IgG4-RD presenting with both aortitis and pachymeningitis 9 . In that case CSF IgG4 level was elevated and this may aid with diagnosis.

Challenges in the diagnosis of IgG4-RD include lack of widespread familiarity with the disease, absence of reliable diagnostic tests short of biopsy, protean manifestations, and many possible mimics. Glucocorticoids are the mainstay of therapy, although data increasingly support a role for rituximab for patients in whom steroids are contraindicated or ineffective ${ }^{10}$.

SARAH LIPTON, MD, Division of Arthritis and Rheumatic Diseases, Oregon Health and Science University, Portland, Oregon; GARTH WARREN, MD, Department of Pathology, University of Colorado, Denver, Colorado; JEFFREY POLLOCK, MD, Assistant Professor, Division of Neuroradiology; PASCALE SCHWAB, MD, Assistant Professor, Division of Arthritis and Rheumatic Diseases, Oregon Health and Science University, 3181 SW Sam Jackson Park Road, Portland, OR 97239, USA.

Address correspondence to Prof. Schwab; E-mail: schwabp@ohsu.edu

\section{ACKNOWLEDGMENT}

Special thanks to Dr. Marjorie Grafe, Division of Neuropathology, for her critical contributions.

\section{REFERENCES}

1. Stone JH, Zen Y, Deshpande V. Mechanisms of disease: IgG4-related disease. N Engl J Med 2012;366:531-51.

2. Kamisawa T, Funata N, Hayashi Y, Eishi Y, Koike M, Tsuruta K, et al. A new clinicopathological entity of IgG4-related autoimmune disease. J Gastroenterol 2003;38:982-4.

3. Khosroshahi A, Cheryk LA, Carruthers M, Edwards JA, Bloch DB Stone JH. K. Prozone effect leads to low IgG4 concentrations in IgG4 related diseases [abstract]. Arthritis Rheum 2012;64 Suppl:2527.

4. Lindstrom KM, Cousar JB, Lopes MB. IgG4-related meningeal disease: clinico-pathological features and proposal for diagnostic criteria. Acta Neuropathol 2010;120:765-76.

5. Stone JR. Aortitis, periaortitis, and retroperitoneal fibrosis, as manifestations of IgG4-related systemic disease. Curr Opin Rheumatol 2011;23:88-94.

6. Chan SK, Cheuk W, Chan KT, Chan JK. IgG4-related sclerosing pachymeningitis: a previously unrecognized form of central nervous system involvement in IgG4-related sclerosing disease. Am J Surg Pathol 2009;33:1249-52.

7. Kosakai A, Ito S, Yamada S, Ideta S, Ota Y, Suzuki N. A case of definite IgG4-related pachymeningitis. Neurology 2010;75:1390.

8. Deshpande V, Zen Y, Chan JK, Yi EE, Sato Y, Yoshino T, et al. Consensus statement on the pathology of IgG4-related disease. Mod Pathol 2012;25:1181-92.

9. Della Torre E, Bozzolo EP, Passerini G, Doglioni MG. IgG4-related pachymeningitis: evidence of intrathecal IgG4 on cerebrospinal fluid analysis. Ann Intern Med 2012;156:401-2.

10. Khosroshahi A, Carruthers MN, Deshpande V, Unizony S, Bloch DB, Stone JH. Rituximab for the treatment of IgG4-related disease: lessons from 10 consecutive patients. Medicine 2012;91:57-66.

J Rheumatol 2013;40:7; doi:10.3899/jrheum.121545 Personal non-commercial use only. The Journal of Rheumatology Copyright @ 2013 . All rights reserved. 